\title{
Effects of selenium biofortification on crop nutritional quality
}

\author{
Mario Malagoli ${ }^{1 *}$, Michela Schiavon ${ }^{1}$, Stefano dall'Acqua ${ }^{2}$ and Elizabeth A. H. \\ Pilon-Smits ${ }^{3}$ \\ 1 Department of Agronomy, Food, Natural Resources, Animals and the Environment, University of Padova, Padova, \\ Italy, ${ }^{2}$ Department of Pharmaceutical and Pharmacological Sciences, University of Padova, Padova, Italy, ${ }^{3}$ Department of \\ Biology, Colorado State University, Fort Collins, CO, USA
}

\section{OPEN ACCESS}

Edited by:

David W. M. Leung,

University of Canterbury, New Zealand

Reviewed by:

Ruediger Hell,

University of Heidelberg, Germany

Gijs A. Kleter,

Wageningen University and Research

Centre, Netherlands

*Correspondence:

Mario Malagoli,

Department of Agronomy, Food, Natural Resources, Animals and the Environment, University of Padova, Agripolis, 35020 Legnaro Padova,

mario.malagoli@unipd.it

Specialty section:

This article was submitted to

Plant Biotechnology,

a section of the journal

Frontiers in Plant Science

Received: 31 October 2014

Paper pending published:

11 December 2014

Accepted: 08 April 2015

Published: 21 April 2015

Citation:

Malagoli M, Schiavon M, dall'Acqua S and Pilon-Smits EAH (2015) Effects of selenium biofortification on crop

nutritional quality.

Front. Plant Sci. 6:280.

doi: 10.3389/fp/s.2015.00280
Selenium (Se) at very low doses has crucial functions in humans and animals. Since plants represent the main dietary source of this element, Se-containing crops may be used as a means to deliver Se to consumers (biofortification). Several strategies have been exploited to increase plant Se content. Selenium assimilation in plants affects both sulfur $(\mathrm{S})$ and nitrogen $(\mathrm{N})$ metabolic pathways, which is why recent research has also focused on the effect of Se fertilization on the production of $\mathrm{S}$ - and $\mathrm{N}$ - secondary metabolites with putative health benefits. In this review we discuss the function of Se in plant and human nutrition and the progress in the genetic engineering of Se metabolism to increase the levels and bioavailability of this element in food crops. Particular attention is paid to Se biofortification and the synthesis of compounds with beneficial effects on health.

Keywords: selenium, plant biofortification, food, nutritional quality, secondary metabolites

\section{The Importance of Selenium to Human and Animal Health}

Selenium is an essential trace element for humans and animals, and some organic forms like methylselenocysteine (MeSeCys) appear to be particularly effective sources of dietary Se. Selenium is incorporated as selenocysteine (SeCys) at the active site of a wide range of selenoproteins involved in major metabolic pathways, such as thyroid hormone metabolism, antioxidant defense and immune function (Rayman, 2012). Low intake of Se in the diet may cause a number of diseases, including heart diseases, hypothyroidism, reduced male fertility, weakened immune system and enhanced susceptibility to infections and cancer (Hatfield et al., 2014; Roman et al., 2014). Selenium deficiency is thought to affect 800 million people worldwide. In livestock, Se deficiency is also responsible for the white muscle disease, with clinical signs that include lesions in skeletal and/or heart muscle. Selenium supplementation of grazing livestock is mandatory in USA and Canada, because there is a marked seasonal and soil-dependent variation in their Se nutrition. For most of the world human and livestock population, vegetables are an important source of Se intake. Thus, increasing Se content in food crops offers an effective approach to reduce the Se deficiency problem in humans and animals.

\section{Selenium Transport and Assimilation in Plants}

While there is no proof of essentiality for Se in plants (Pilon-Smits et al., 2009), Se is readily taken up by plants in the form of selenate through the sulfate transporters (Figure 1). Due to their chemical similarities (Shibagaki et al., 2002; El Kassis et al., 2007), Se and sulfur (S) compete for the same transporters, and Se uptake is generally limited by high S levels. After uptake, selenate can access the sulfate assimilation pathway and be reduced via selenite to selenide (Figure 1). Selenide can be incorporated into the S-analog amino acid selenocysteine (SeCys), which may further be converted 


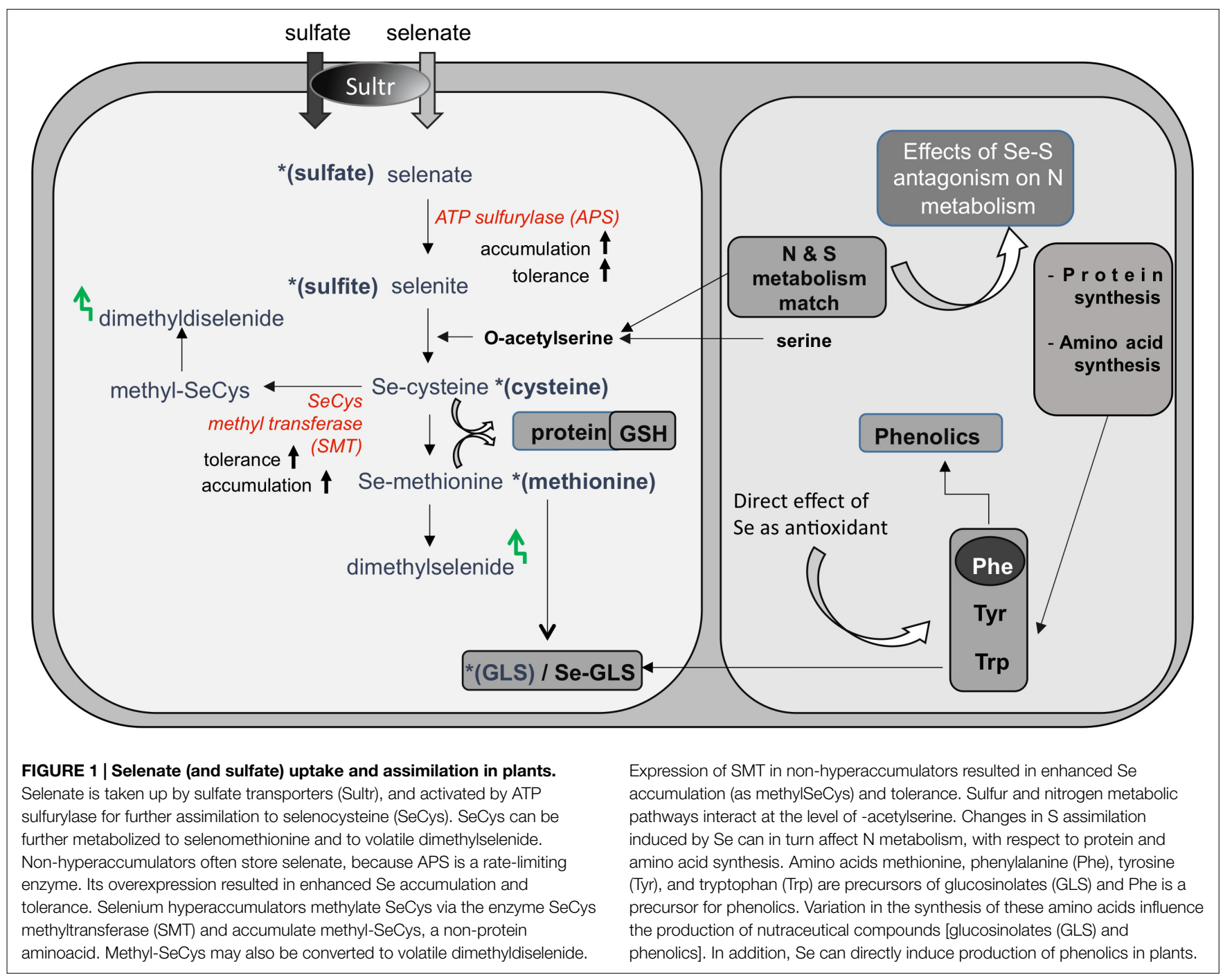

in three enzymatic steps to selenomethionine (SeMet; for a review, see Sors et al., 2005). The mistaken insertion of these Se-amino acids into proteins instead of cysteine and methionine may cause metabolic dysfunction (Sabbagh and Van Hoewyk, 2012). Incorporation of Se into proteins may be avoided by diverting Se to other, less toxic forms. Some plants accumulate the nonprotein organic Se-compounds methylselenocysteine (MeSeCys), $\gamma$-glutamyl-MeSeCys and/or selenocystationine, sometimes to very high tissue levels without ill effects (Terry et al., 2000). Selenium can also be volatilized from plants in the forms of dimethylselenide or dimethyldiselenide, which are produced from SeMet and methyl-SeCys, respectively (Figure 1). The different selenocompounds found in plants have different toxicity levels and different nutritional value, with organic forms generally being more efficient in Se biofortification. Therefore, it is important to know which forms of Se are present in plant material used for nutritional supplementation. If we know which enzymes control the various metabolic steps it is also possible to genetically engineer more nutritious forms of Se in crop plants by enhancing the levels of critical enzymes.

\section{Selenium Biofortification Efforts}

Selenium is chemically analogous to $S$ and therefore accumulated by all plants to some extent, in all plant parts. The plant Se levels found in nature and in crops depends on soil Se abundance and the levels of competing $S$ compounds (Figure 2). In addition, plant Se concentrations at a given seleniferous site, i.e., a site containing more than 1 (and up to 100 ) $\mathrm{mg} \mathrm{Se} \mathrm{kg}^{-1}$ soil, may vary over 100-fold between plant species (Galeas et al., 2007). Different plant species differ with respect to their capacity to accumulate Se, which likely correlates with their expression levels of sulfate transporters. Plant species also vary with respect to which forms of Se they accumulate due to the presence and activity of various $\mathrm{S} / \mathrm{Se}$ metabolic enzymes. Selenium biofortification efforts may make use of this natural variation between plant species, and choose crop species that naturally tend to contain higher Se (and S) levels, such as Brassica and Allium species (Terry et al., 2000). Since Se biofortification is most effective when organic Se is supplied, plant species known to accumulate organic forms of Se may be preferred, including broccoli and garlic (Lyi et al., 2005; 


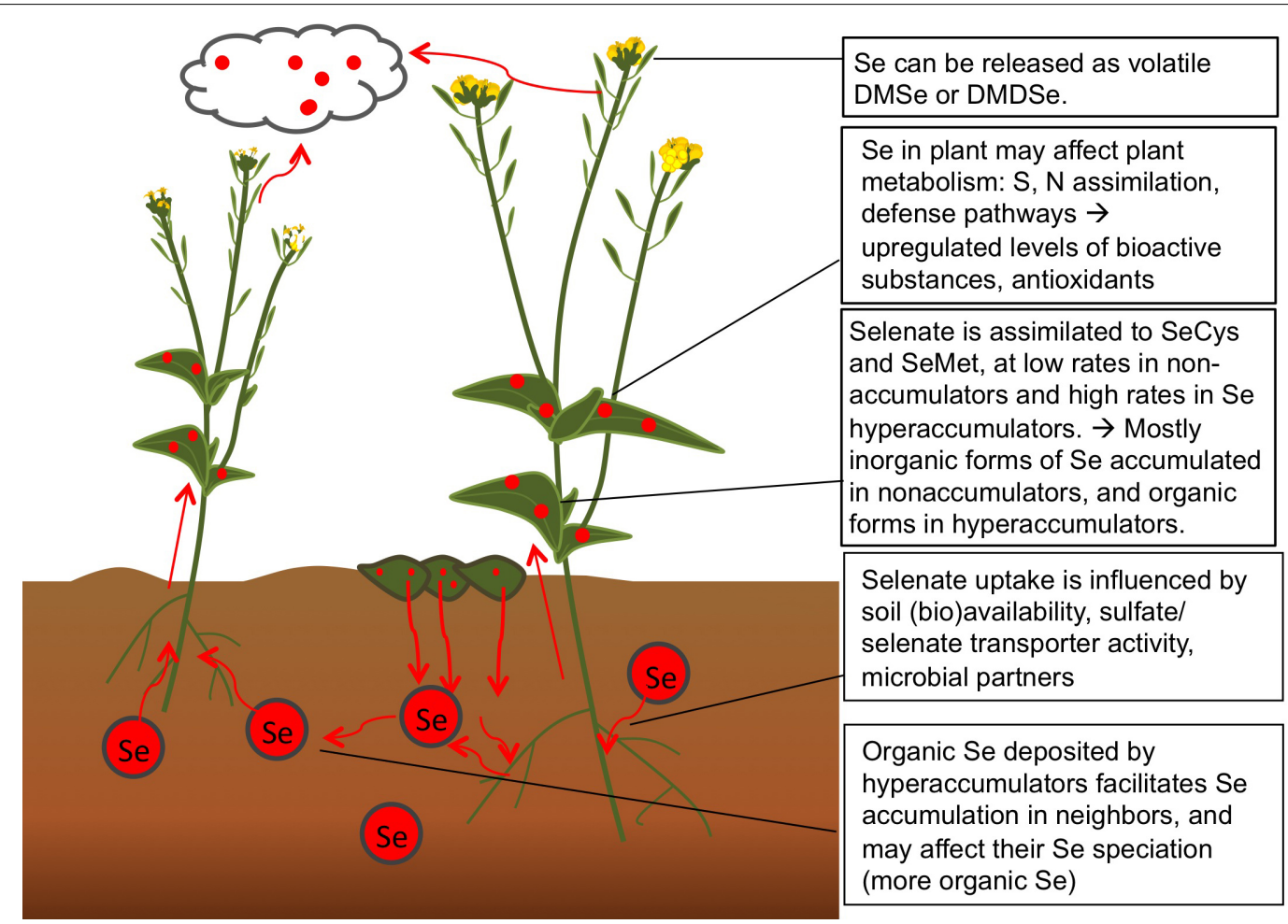

FIGURE 2 | Processes related to Se in the soil-plant system, relevant for Se biofortification. Selenate is taken up from soil and assimilated (particularly by Se hyperaccumulators) to organic forms of Se. Some Se is accumulated and some volatiled as nontoxic dimethyl(di)selenide.

Hsu et al., 2011). Care has to be taken to not supply unnecessary $S$ in Se-fortified crop production, since $S$ will reduce Se uptake. In soils where Se levels are very low, as e.g., in Finland, the United Kingdom, parts of China, and New Zealand (Chen et al., 2002; Broadley et al., 2006; Alfthan et al., 2014), it is not enough to just plant Se-accumulating crop species, but also necessary to provide inorganic Se as fertilizer for the crop. This practice is in effect in Finland since the 1980s, and has led to significantly enhanced blood Se levels in the general population (Alfthan et al., 2014). Whether this is concomitant with positive health effects remains to be investigated; a complicating factor is that there is no reference population. In Se-deficient areas of China, too, Se biofortification of crops is practiced to prevent the devastating Keshan disease still prevalent in vast areas, which is characterized by cardiomyopathy caused by Se deficiency (Bañuelos et al., 2013).

\section{Genetic Engineering of Plant Se Metabolism and its Potential for Biofortification}

Genetic engineering, which has been shown to enhance Se accumulation, tolerance, and volatilization by plants, has focused on S-related enzymes. First, overexpression in Brassica juncea of ATP sulfurylase (APS), a key enzyme for selenate-to-selenite transition, resulted in enhanced selenate reduction: the transgenic APS plants accumulated organic Se (likely methyl-SeCys) when supplied with selenate, while wildtype controls accumulated sele- nate (Pilon-Smits et al., 1999). The APS transgenics accumulated and tolerated more Se as well (Figure 1). In another approach, SeCys methyltransferase (SMT) was overexpressed in A. thaliana and B. juncea (Ellis et al., 2004; LeDuc et al., 2004). The SMT transgenics showed enhanced Se accumulation, and the form was methyl-SeCys (Figure 1). In both APS and SMT transgenics more Se is accumulated, and their form of Se is more suitable for biofortification (Figure 2).

When APS and SMT B. juncea transgenics were crossed to create double-transgenic plants, these accumulated up to 9 times higher Se levels than wild type (LeDuc et al., 2006). Most of the Se in the double transgenics was in the form of methyl-SeCys: the APSxSMT plants accumulated up to eightfold more methylSeCys than wild type and nearly twice as much as the SMT transgenics.

When grown on naturally seleniferous soil in a greenhouse pot experiment, the APS transgenics accumulated Se to threefold higher levels than wildtype B. juncea (Van Huysen et al., 2004). In two field experiments carried out on selenate-contaminated soil in central California, the APS transgenics accumulated fourfold higher Se levels than wildtype B. juncea, and SMT transgenics showed twofold higher Se levels (Bañuelos et al., 2005, 2007). Biomass production was comparable for the different plant types. Thus, genetic engineering has produced new genotypes of B. juncea with enhanced Se accumulation and higher levels of nutritious organic Se, all promising for use as Se-fortified foods.

In addition to the $S$ assimilation enzymes, sulfate transporters may be potential targets of genetic engineering; selenate 
transporters from Se hyperaccumulators will be particularly interesting in this respect.

\section{Effects of Se Biofortification on Secondary Plant Compounds}

Variations in plant $S$ uptake and assimilation induced by Se may cause changes in the synthesis of S-secondary compounds with nutritional value, such as glucosinolates (GLS), which function in plant defense against insects and herbivores (Figure 1). The hydrolysis of GLS within cells produces isothiocyanates, which act as cancer-preventing agents in mammals (Dinkova-Kostova, 2013).

Because $\mathrm{S}$ nutrition is strictly associated with $\mathrm{N}$ metabolism, Se can exert an additional effect on the synthesis of proteins and amino acids, as well as on $\mathrm{N}$-secondary compounds with free radical scavenging activities, like phenolics (Figure 1). Amino acids such as methionine, phenylalanine (Phe), tyrosine (Tyr) and tryptophan (Trp) are precursors of GLS. Furthermore, Phe is the substrate for phenolics biosynthesis. Variation in the synthesis of these amino acids influence the production of both types of beneficial compounds.

Several studies examined how Se enrichment of plants affects their content in these phytochemicals (Robbins et al., 2005; Barickman et al., 2013; Schiavon et al., 2013). Tomato (Solanum lycopersicon L.) plants and Brassica species in particular, contain high levels of phenolic compounds. Additionally, Brassica spp. are rich in glucosinolates (GLSs).

In broccoli (Brassica oleracea L.), Se fertilization was shown to reduce the amount of total phenolic acids, without altering the profile distribution of specific compounds (Robbins et al., 2005). In contrast, Se at low dosages (5 and $10 \mu \mathrm{M})$ increased the leaf phenolic content of hydroponically grown tomato plants (Schiavon et al., 2013). Furthermore, the supply of selenate via foliar spray at 2 and $20 \mathrm{mg} \mathrm{Se} \mathrm{plant}^{-1}$ resulted in Se-biofortified tomato fruits, with enhanced levels of the antioxidant flavonoids naringenin, chalcone and kaempferol (Schiavon et al., 2013).

Selenium fertilization may also affect the levels of GLS, a class of secondary plant $S$ compounds. GLS may have anticarcinogenic properties, based on studies using experimental in vitro and in vivo models, but can also cause toxicity at elevated levels (Assayed and Abd El-Aty, 2009). The presence of GLS and GLS-metabolites at high level in animal feed can cause the decrease in growth and production, affecting organs such as liver, kidney, lungs and inducing morphological and physiological changes of thyroid (Tripathi and Mishra, 2007). Robbins et al. (2005) reported a weak reduction of indole, aliphatic, total glucosinolates, and glucoraphanin after Se fertilization, and a strong fall of sulforaphane production. A Serelated decrease of these compounds in broccoli was also observed by Barickman et al. (2013), but high levels of GLSs could be maintained with Se concentration lower than $0.8 \mathrm{mg} \mathrm{L}^{-1}$ or by

\section{References}

Alfthan, G., Eurola, M., Ekholm, P., Venäläinen, E. R., Root, T., Korkalainen, K., et al. (2014). Effects of nationwide addition of selenium to fertilizers on foods, and animal and human health in Finland: From deficiency to increasing $\mathrm{S}$ concentration in the medium. Exposing plants to low Se concentrations can promote $S$ uptake and assimilation in some species, including B. juncea (Harris et al., 2014), thus potentially increasing the level of S-organic compounds. However, while upregulating $S$ uptake and assimilation, Se treatment was also found to upregulate genes involved in GLSs breakdown in A. thaliana (Van Hoewyk et al., 2008).

Recently, Ávila et al. (2013, 2014) showed the reduction of GLSs in the florets of broccoli treated with selenate, whereas in the sprouts GLS levels were not affected. Moreover, sprouts contained nearly sixfold higher content of the potent anticancer glucoraphanin than florets. Se-enriched sprouts were expected to exhibit greater potential anticancer activity because of high accumulation of SeMCys with similar glucosinolate production. Brassica crops supplied with selenate were able to form selenoglucosinolates, with a methylselenoalkyl group that was likely derived from selenomethionine (Matich et al., 2012). Selenoglucosinolates accounted for $60 \%$ of the concentrations of their S analogs (Matich et al., 2012). The production of selenoglucosinolates following Sefertilization has implications for human health, as the synthetic Se-containing isothiocyanates are reported to be more potent anticancer compounds than their S counterparts (Emmert et al., 2010). As mentioned, the Se-GLS and/or GLS content must be monitored when plants or their residues are used for human or animal consumption, to avoid potential toxicity effects.

\section{Future Prospects}

Studies so far indicate that it is possible to maximize multiple bioactive components in a single plant. However, because in some cases the accumulation of Se may interfere with the production of some classes of phytochemicals, the Se biofortification programs must consider the interactions between Se and the main metabolic pathways of the plant. Particular attention should be paid to the reciprocal effects of Se and S on their accumulation and assimilation into organic compounds. In this context, managing $\mathrm{S}$ concentration during Se fertilization to vary S:Se ratios could be envisioned as a strategy to increase Se to beneficial dietary levels in plants without compromising GLS and other health-promoting compound contents.

An interesting new area of research involves the use of plantmicrobe interactions to enhance Se biofortification. Another avenue to explore is the cultivation of Se fortified crops on seleniferous soil, thereby improving the amenity of that soil for further agriculture, and using the produced biomass to fortify the diets of people (and their livestock) in Se-deficient areas. Finally, since different plant species appear to be able to influence their neighboring plants' Se accumulation and perhaps speciation (El Mehdawi et al., 2012), it will be interesting to further explore the potential of various co-cropping techniques to optimize crop Se biofortification and nutritional quality.

optimal selenium status of the population. J. Trace Elem. Med. Biol. doi: 10.1016/j.jtemb.2014.04.009 [Epub ahead of print].

Assayed, M. E., and Abd El-Aty, A. M. (2009). Cruciferous plants: phytochemical toxicity versus cancer chemoprotection. Mini Rev. Med. Chem. 9, 1470-1478. doi: 10.2174/138955709790361511 
Ávila, F. W., Faquin, V., Yang, Y., Ramos, S. J., Guilherme, L. R., Thannhauser, T. W., et al. (2013). Assessment of the anticancer compounds Semethylselenocysteine and glucosinolates in Se-biofortified broccoli (Brassica oleracea L. var. italica) sprouts and florets. J. Agric. Food Chem. 61, 6216-6223. doi: 10.1021/jf4016834

Ávila, F. W., Yang, Y., Faquin, V., Ramos, S. J., Guilherme, L. R., Thannhauser, T. W., et al. (2014). Impact of selenium supply on Se-methylselenocysteine and glucosinolate accumulation in selenium-biofortified Brassica sprouts. Food Chem. 15, 578-586. doi: 10.1016/j.foodchem.2014.05.134

Bañuelos, G., LeDuc, D. L., Pilon-Smits, E. A. H., Tagmount, A., and Terry, N. (2007). Transgenic Indian mustard overexpressing selenocysteine lyase or selenocysteine methyltransferase exhibit enhanced potential for selenium phytoremediation under field conditions. Environ. Sci. Technol. 41, 599-605. doi: 10.1021/es061152i

Bañuelos, G. S., Lin, Z.-Q., and Yin, X. (2013). Selenium in the Environment and Human Health. Leiden: CRC Press. doi: 10.1201/b15960

Bañuelos, G., Terry, N., LeDuc, D. L., Pilon-Smits, E. A. H., and Mackey, B. (2005). Field trial of transgenic Indian mustard plants shows enhanced phytoremediation of selenium-contaminated sediment. Environ. Sci. Technol. 39, 1771-1777. doi: 10.1021/es049035f

Barickman, T. C., Kopsell, D. A., and Sams, C. E. (2013). Selenium influences glucosinolate and isothiocyanates and increases sulfur uptake in Arabidopsis thaliana and rapid-cycling Brassica oleracea. J. Agric. Food Chem. 61, 202-209. doi: 10.1021/jf3037227

Broadley, M. R., White, P. J., Bryson, R. J., Meacham, M. C., Bowen, H. C., Johnson, S. E., et al. (2006). Biofortification of UK food crops with selenium (Se). Proc. Nutr. Soc. 65, 169-181. doi: 10.1079/PNS2006490

Chen, L., Yang, F., Xu, J., Hu, Y., Hu, Q., and Zhang, Y., et al. (2002). Determination of selenium concentration of rice in china and effect of fertilization of selenite and selenate on selenium content of rice. J. Agric. Food Chem. 50, 5128-5130. doi: $10.1021 /$ jf0201374

Dinkova-Kostova, A. T. (2013). Chemoprotection against cancer by isothiocyanates: a focus on the animal models and the protective mechanisms. Top. Curr. Chem. 329, 179-201. doi: 10.1007/128_2012_337

El Kassis, E., Cathala, N., Rouached, H., Fourcroy, P., Berthomieu, P., Terry, N., et al. (2007). Characterization of a selenate-resistant Arabidopsis mutant. Root growth as a potential target for selenate toxicity. Plant Physiol. 143, 1231-1241. doi: $10.1104 /$ pp.106.091462

El Mehdawi, A. F., Cappa, J. J., Fakra, S. C., Self, J., and Pilon-Smits, E. A. H. (2012). Interactions of selenium and non-accumulators during co-cultivation on seleniferous or non-seleniferous soil-the importance of having good neighbors. New Phytol. 194, 264-277. doi: 10.1111/j.1469-8137.2011.04043.x

Ellis, D. R., Sors, T. G., Brunk, D. G., Albrecht, C., Orser, C., Lahner, B., et al. (2004). Production of Se-methylselenocysteine in transgenic plants expressing selenocysteine methyltransferase. BMC Plant Biol. 4:1-11. doi: 10.1186/14712229-4-1

Emmert, S. W., Desai, D., Amin, S., and Richie, J. P. (2010). Enhanced Nrf2dependent induction of glutathione in mouse embryonic fibroblasts by isoselenocyanate analog of sulforaphane. Bioorg. Med. Chem. Lett. 20, 2675-2679. doi: 10.1016/j.bmcl.2010.01.044

Galeas, M. L., Zhang, L. H., Freeman, J. L., Wegner, M., and Pilon-Smits, E. A. H. (2007). Seasonal fluctuations of selenium and sulfur accumulation in selenium hyperaccumulators and related non-accumulators. New Phytol. 173, 517-525. doi: $10.1111 / j .1469-8137.2006 .01943 . x$

Harris, J., Schneberg, K. A., and Pilon-Smits, E. A. H. (2014). Sulfur-selenium-molybdenum interactions distinguish selenium hyperaccumulator Stanleya pinnata from non-hyperaccumulator Brassica juncea (Brassicaceae). Planta 239, 479-491. doi: 10.1007/s00425-013-1996-8

Hatfield, D. L., Tsuji, P. A., Carlson, B. A., and Gladyshev, V. N. (2014). Selenium and selenocysteine: roles in cancer, health, and development. Trends Biochem. Sci. 39, 112-120. doi: 10.1016/j.tibs.2013.12.007

Hsu, F.-C., Wirtz, M., Heppel, S., Bogs, J. Kramer, U., Khan, M. S., Bub, A., et al. (2011). Generation of Se-fortified broccoli as functional food: impact of Se fertilization on S metabolism. Plant Cell Environ. 34, 192-207. doi: 10.1111/j.1365-3040.2010.02235.x

LeDuc, D. L., AbdelSamie, M., Montes-Bayón, M., Wu, C. P., Reisinger, S. J., and Terry, N. (2006). Overexpressing both ATP sulfurylase and selenocys- teine methyltransferase enhances selenium phytoremediation traits in Indian mustard. Environ. Pollut. 44, 70-76. doi: 10.1016/j.envpol.2006.01.008

LeDuc, D. L., Tarun, A. S., Montes-Bayon, M., Meija, J., Malit, M. F., Wu, C. P., et al. (2004). Overexpression of selenocysteine methyltransferase in Arabidopsis and indian mustard increases selenium tolerance and accumulation. Plant Physiol. 135, 377-383. doi: 10.1104/pp.103.026989

Lyi, S. M., Heller, L. I., Rutzke, M., Welch, R. M., Kochian, L. V., and Li, L. (2005). Molecular and biochemical characterization of the selenocysteine Semethyltransferase gene and Se-methylselenocysteine synthesis in broccoli. Plant Physiol. 138, 409-420. doi: 10.1104/pp.104.056549

Matich, A. J., McKenzie, M. J., Lill, R. E., Brummell, D. A., McGhie, T. K., Chen, R. K., et al. (2012). Selenoglucosinolates and their metabolites produced in Brassica spp. fertilised with sodium selenate. Phytochemistry 75, 140-152. doi: 10.1016/j.phytochem.2011.11.021

Pilon-Smits, E. A. H., Hwang, S. B., Lytle, C. M., Zhu, Y. L., Tai, J. C., Bravo, R. C., et al. (1999). Overexpression of ATP sulfurylase in Brassica juncea leads to increased selenate uptake, reduction and tolerance. Plant Physiol. 119, 123-132. doi: $10.1104 /$ pp.119.1.123

Pilon-Smits, E. A. H., Quinn, C. F., Tapken, W., Malagoli, M., and Schiavon, M. (2009). Physiological functions of beneficial elements. Curr. Opin. Plant Biol. 12, 267-274. doi: 10.1016/j.pbi.2009.04.009

Rayman, M. P. (2012). Selenium and human health. Lancet 379, 1256-1268. doi: 10.1016/S0140-6736(11)61452-9

Robbins, R. J., Keck, A.-S., Banuelos, G., and Finley, J. W. (2005). Cultivation conditions and selenium fertilization alter the phenolic profile, glucosinolate, and sulforaphane content of broccoli. J. Med. Food 8, 204-214. doi: 10.1089/jmf.2005.8.204

Roman, M., Jitaru, P., and Barbante, C. (2014). Selenium biochemistry and its role for human health. Metallomics 6, 25-54. doi: 10.1039/C3MT00185G

Sabbagh, M., and Van Hoewyk, D. (2012). Malformed selenoproteins are removed by the ubiquitin-proteasome pathway in Stanleya pinnata. Plant Cell Physiol. 53, 555-564. doi: 10.1093/pcp/pcs015

Schiavon, M., Dall'acqua, S., Mietto, A., Pilon-Smits, E. A., Sambo, P., Masi, A., et al. (2013). Selenium fertilization alters the chemical composition and antioxidant constituents of tomato (Solanum lycopersicon L.). J. Agric. Food Chem. 61, 10542-10554. doi: 10.1021/jf4031822

Shibagaki, N., Rose, A., McDermott, J. P., Fujiwara, T., Hayashi, H., Yoneyama, T., et al. (2002). Selenate-resistant mutants of Arabidopsis thaliana identify Sultr1;2, a sulfate transporter required for efficient transport of sulfate into roots. Plant J. 29, 475-486. doi: 10.1046/j.0960-7412.2001.01232.x

Sors, T. G., Ellis, D. R., and Salt, D. E. (2005). Selenium uptake, translocation, assimilation and metabolic fate in plants. Photosynth. Res. 86, 373-389. doi: 10.1007/s11120-005-5222-9

Terry, N., Zayed, A. M., de Souza, M. P., and Tarun, A. S. (2000). Selenium in higher plants. Annu. Rev. Plant Physiol. Mol. Biol. 51, 401-432. doi: 10.1146/annurev. arplant.51.1.401

Tripathi, M. K., and Mishra, A. S. (2007). Glucosinolate in animal nutrition: a review. Anim. Feed Sci. Tech. 132, 1-27. doi: 10.1016/j.anifeedsci.2006.03.003

Van Hoewyk, D., Takahashi, H., Hess, A., Tamaoki, M., and Pilon-Smits, E. A. H. (2008). Transcriptome and biochemical analyses give insights into seleniumstress responses and selenium tolerance mechanisms in Arabidopsis. Physiol. Plant. 132, 236-253. doi: 10.1111/j.1399-3054.2007.01002.x

Van Huysen, T., Terry, N., and Pilon-Smits, E. A. H. (2004). Exploring the selenium phytoremediation potential of transgenic Brassica juncea overexpressing ATP sulfurylase or cystathionine- $\gamma$-synthase. Int. J. Phytoremed. 6, 111-118. doi: $10.1080 / 16226510490454786$

Conflict of Interest Statement: The authors declare that the research was conducted in the absence of any commercial or financial relationships that could be construed as a potential conflict of interest.

Copyright (C) 2015 Malagoli, Schiavon, dall'Acqua and Pilon-Smits. This is an openaccess article distributed under the terms of the Creative Commons Attribution License (CC BY). The use, distribution or reproduction in other forums is permitted, provided the original author(s) or licensor are credited and that the original publication in this journal is cited, in accordance with accepted academic practice. No use, distribution or reproduction is permitted which does not comply with these terms. 